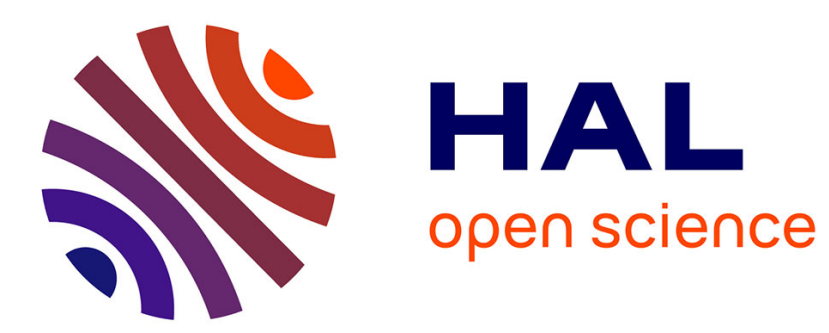

\title{
Optimal insurance against climatic experience
}

Olivier Mahul

\section{To cite this version:}

Olivier Mahul. Optimal insurance against climatic experience. 1999. hal-01952115

\section{HAL Id: hal-01952115 \\ https://hal.science/hal-01952115}

Preprint submitted on 11 Dec 2018

HAL is a multi-disciplinary open access archive for the deposit and dissemination of scientific research documents, whether they are published or not. The documents may come from teaching and research institutions in France or abroad, or from public or private research centers.
L'archive ouverte pluridisciplinaire HAL, est destinée au dépôt et à la diffusion de documents scientifiques de niveau recherche, publiés ou non, émanant des établissements d'enseignement et de recherche français ou étrangers, des laboratoires publics ou privés.

\section{(이)(\$)}

Distributed under a Creative Commons Attribution - NonCommercial - NoDerivatives| 4.0 


\section{INRA - ECONOMIE \\ DOCUMENTATION \\ Rue Adolphe Bobierre \\ CS 61103 \\ 35011 RENNES CEDEX}

Tél. 02.99.28.54.09

\section{Optimal Insurance Against Climatic Experience}

Olivier MAHUL

INRA Department of Economics

Rue Adolphe Bobierre

CS 61103

35011 Rennes cedex France

Email:mahul@roazhon.inra.fr

Tel.: (33) 299285382

Fax: (33) 299285380

August 1999 


\title{
Optimal Insurance Against Climatic Experience
}

\begin{abstract}
An optimal insurance contract against a climatic risk is derived in the presence of an uninsurable production risk. Its design depends on the stochastic dependency between both sources of uncertainty and on the producer's attitude towards risk, especially on his prudent behavior. The Named Peril Crop Insurance program is reconsidered when indemnity payments are based on the intensity of the insurable weather variable rather than on its consequences on yield. The prudent producer responds to this actuarially fair insurance contract by increasing his exposure towards risk. Finally, rational weather based insurance purchasing decisions are used to examine the optimal hedging strategy with weather derivatives on financial markets.
\end{abstract}

Keywords: climatic risk; prudence; stochastic dominance; weather derivatives. 


\section{Introduction}

The failure of the multiple peril crop insurance program in which indemnity payments are based on the producer's individual yields induced the U.S. government to promote alternative insurance policies. Since 1993, the Risk Management Agency thus offers the U.S. farmers area yield contracts under its Group Risk Plan in selected countries (Skees, Black and Barnett). Mahul analyzes the optimal design of this insurance policy in which the indemnity is contingent on the aggregate yield of a surrounding area. Another alternative insurance contract consists in basing the indemnity upon a weather index, such as rainfall or temperature. This policy was proposed in the past by Sanderson but has failed to gain acceptance among policy makers. In particular, the difficulties of a rainfall insurance program were a subject of debate in Australia (e.g., Bardsley, Abey and Davenport; Quiggin 1986; Patrick). The recent development of weather based instruments on financial markets, known as weather derivatives, for which the payoff depend on the cause of risk rather than on its effect on yield, provide new opportunities of covering exposure to unfavorable weather events.

The purpose of this paper is fourfold. First, from a stochastic production function affected by a climatic risk and by an aggregate production risk, the design of an optimal insurance contract against a weather variable is derived. Its schedule depends on the stochastic dependence between the insurable climatic risk and the uninsurable aggregate production risk, and on the producer's attitude towards risk. The concept of prudence, introduced and justified by Kimball, is used to derive the optimal insurance design. Second, the named peril crop insurance program is reconsidered so that the indemnity is contingent on the intensity of the weather variable rather than on its consequences on yield, and the producer's insurance purchasing decision is examined in this context of incomplete markets. Third, the impact of the reconsidered named peril crop insurance policy on the optimal level of input use is analyzed. Finally, the optimal hedging strategy with weather derivatives is investigated through the similarity between weather based insurance contracts and financial instruments. 
After having described the stochastic production function in the next section, the above purposes are successively examined in the following four sections and concluding comments are provided in the last section.

\section{The Stochastic Production Function}

Contrary to standard crop insurance contracts, indemnity payments of weather insurance are based on the intensity of the weather index rather on than its effect on yield. Nevertheless, the producer seeks to stabilize his revenue which is affected by the consequences of these climatic changes. Consequently, the first step is to specify a model of crop yield in order to explicit the impact of weather uncertainty and other production risks on yield. Biophysical models of yield have been recently developed to examine the changes in yield that are generated by changes in the physical climate (Kaufmann and Snell). Crop weather models simulate explicitly the crop-climate interface and multiple regression yield models use statistical technique to estimate the effect of physical variables on yield from empirical observations. Our purpose here is much more modest. We aim at determining a stochastic production function which models the impact on yield of an insurable random weather variable, of an uninsurable aggregate production risk and of the input level select by the producer.

The first originality of this production function is that it allows yield to depend on two sources of risk. In addition, it is assumed to be linear in random variables:

$$
\tilde{y}=g(x) \tilde{\omega}+k(x) \tilde{\varepsilon}+h(x)
$$

where $\tilde{y}$ is random output, $x$ is input, $\widetilde{\omega}$ is random weather index with $E \widetilde{\omega}=\mu>0$ and $\widetilde{\varepsilon}$ denotes an aggregate production risk. The index $\widetilde{\omega}$ depends on the insured weather event and on the location of the event to be measured. It can thus measure the cumulative rainfall level or the cumulative degree-day heat level in a given geographical area for a given period. The functions $g($.$) and k($.) are assumed nonnegative. Hence, smaller realizations of $\widetilde{\omega}$ and $\widetilde{\varepsilon}$ correspond to relatively more severe disasters. This functional form can be viewed as a linear 
approximation of a more general production function $f(x, \widetilde{\omega}, \widetilde{\varepsilon})$ around $(E \tilde{\omega}, E \widetilde{\varepsilon})$. It should be noted that the Just and Pope production function is obtained when $\widetilde{\varepsilon}$ equals zero almost surely. The cumulative distribution function of $(\widetilde{\omega}, \widetilde{\varepsilon})$ is denoted $T(\omega, \varepsilon)$ and it is defined over the support $\left[\omega_{\min }, \omega_{\max }\right] \times\left[\varepsilon_{\min }, \varepsilon_{\max }\right]$ with $0<\omega_{\min }<\omega_{\max }$ and $\varepsilon_{\min }<0<\varepsilon_{\max }$. The marginal distribution function of $\widetilde{\varepsilon}$ is denoted $\Phi(\omega)$.

The second originality of this stochastic production function is that both random variables which affect the level of output can be independent or correlated. The stochastic dependence is characterized by stochastic dominance. More specifically, we assume that a decrease in $\omega$ induces a riskier conditional distribution of $\widetilde{\varepsilon}$ by first- or second-order stochastic dominance, respectively:

$$
\begin{aligned}
& \Psi_{\omega}(\varepsilon / \widetilde{\omega}=\omega) \leq 0 \text { for all } \varepsilon \text { and } \omega \\
& \int_{\varepsilon_{\text {min }}}^{\varepsilon} \Psi_{\omega}(s / \widetilde{\omega}=\omega) d s \leq 0 \text { for all } \varepsilon \text { and } \omega
\end{aligned}
$$

where $\Psi(. / \widetilde{\omega}=\omega)$ is the cumulative distribution function of $\widetilde{\varepsilon}$ conditional on $\widetilde{\omega}=\omega$, with $\Psi_{\omega} \equiv \partial \Psi / \partial \omega$. It is well-known that the first-order stochastic dominance (FSD) criterion expressed in equation (2) is more restrictive than the second-order stochastic dominance (SSD) criterion characterized in equation (3). If the weather variable $\widetilde{\omega}$ denotes the cumulative rainfall level or the cumulative degree-day heat unit reported by the regional weather station and $\widetilde{\varepsilon}$ is the aggregate variable of the other sources of risk affecting the individual yields, such a correlation means that drought or excessive heat increases the other sources of production uncertainty in the sense of FSD or SSD. The linear form of the production function in the random variables allow us to stress the impact of a stochastic dependency between an insurable climatic risk and an uninsurable aggregate production risk on the farmer's optimal insurance purchasing decision. Nevertheless, this form prevents us from considering simultaneously the negative effects of droughts and floods on individual yields, but they can be examined 
separately through an appropriate definition of the realizations of the weather index.

\section{The Design of an Optimal Insurance Contract against a Climatic Risk}

The risk-averse producer is endowed with initial wealth $\pi_{0}$ and the stochastic production function expressed in (1). The input and output prices are assumed to be nonrandom. The price of one unit of input is denoted $p$ and the output price is normalized to unity without a loss of generality. Therefore, the producer faces only production uncertainty. He can purchase an insurance contract which provides him with protection against a specific climatic experience, such as droughts or frosts. Nevertheless, the other sources of production risk are uninsurable and thus he has to bear their consequences. We focus in this section on the design of an optimal insurance contract against a weather index in this context of incomplete markets and consequently the level of input selected by the producer is assumed to be fixed. The impact of the insurance contract on the level of input use will be examined in a subsequent section.

The insurance contract against a specific weather event is described by couple $[I(), P$.$] where P$ is the insurance premium and $I(\omega)$ is the indemnity payments received by the insured producer if the insurer observes the realized weather index $\omega$. A feasible coverage function satisfies:

$$
I(\omega) \geq 0 \text { for all } \omega
$$

The risk-averse producer with utility function $u$, where $u^{\prime}>0$ and $u^{\prime \prime}<0$, maximizes the expected utility of his final wealth $\pi$. He purchases the insurance contract $[I(), P$.$] if his expected utility level is greater with this policy than$ without it:

$$
E u\left(\pi_{0}^{\prime}+\tilde{y}+I(\tilde{\omega})-P\right) \geq E u\left(\pi_{0}^{\prime}+\tilde{y}\right)
$$

where $\pi_{0}^{\prime}=\pi_{0}-p x$.

The insurance company with initial wealth $w_{0}$ maximizes the expected value of its utility function $v$, with $v^{\prime}>0$ and $v^{\prime \prime} \leq 0$. It faces firm-specific costs of risk 
bearing such as convex tax functions and/or transaction costs associated with bankruptcy, agency costs caused by conflicts between shareholders or information asymmetries between managers of the firm and providers of capital (Doherty and Dionne). The transaction cost function $c($.$) is thus assumed increasing and convex$ with indemnity payments:

$$
c(0)=0, c^{\prime}(I) \geq 0 \text { and } c^{\prime \prime}(I) \geq 0 \text { for all } I
$$

The insurer offers the insurance contract $[I(), P$.$] if and only if$

$$
E v\left[w_{0}+P-I(\widetilde{\omega})-c(I(\tilde{\omega}))\right] \geq v\left(w_{0}\right)
$$

The participation constraints (5) and (7) define the set of insurance contracts which are acceptable to both parties. This set is assumed not to be empty and therefore the climatic risk $\widetilde{\omega}$ is assumed insurable. This hypothesis seems realistic if the weather event is hail. Nevertheless, this insurance scheme may not be viable for other unfavorable weather events, like droughts or extreme temperatures, which affect simultaneously a large number of farms. The high correlation among individual farm-level yields may force the insurer to charge a high risk premium which makes insurance purchases unattractive. Hence, the presence of a strong systemic component in the climatic risk may be responsible for its uninsurability. The presence of systemic risk as a main obstacle of insurability was developed by Quiggin (1994) in the case of rainfall insurance and more recently by Miranda and Glauber. Nevertheless, financial markets have the resources to support the economic consequence of natural hazards and their role as an alternative way of spreading climatic risk will be examined afterwards.

The design of an optimal insurance contract against a specific weather event is denoted by couple $[I(), P$.$] that maximizes the producer's expected utility of final$ wealth subject to the constraint that indemnity payments are nonnegative and that the insurer's expected utility is constant:

$$
\begin{aligned}
& \max _{I() . P} E u\left(\pi_{0}^{\prime}+\tilde{y}+I(\widetilde{\omega})-P\right) \\
& \text { subject to conditions (1), (4) and (7). }
\end{aligned}
$$


The insurance premium $P$ is first taken as given and problem (8) is solved via optimal control theory (Raviv). The following proposition states that the optimal insurance contract depends on the stochastic relationship between both insurable and uninsurable risks and on the producer's attitude towards risk.

\section{PROPOSITION 1.}

If one of the following three assumptions are satisfied:

(i) the producer is risk-averse and the uninsurable aggregate production risk is independent of the insurable weather index;

(ii) the producer is risk-averse and a decrease in the insurable weather index makes the uninsurable aggregate production variable riskier according to (2);

(iii) the risk-averse producer is prudent and a decrease in the insurable weather index makes the uninsurable aggregate production variable riskier according to (3);

then a trigger weather index $\hat{\omega} \in\left[\omega_{\min }, \omega_{\max }\right]$ exists such that the optimal indemnity, when the premium and the level of input use are fixed, takes the form

$$
I^{*}(\omega) \begin{cases}=0 & \text { if } \omega \geq \hat{\omega} \\ >0 & \text { if } \omega<\hat{\omega}\end{cases}
$$

When $I^{*}(\omega)>0$, the marginal coverage satisfies

$$
I^{*}(\omega)=g(x) \frac{\int_{\varepsilon_{\min }}^{\varepsilon_{\max }} u^{\prime \prime}(\pi) d \Psi(\varepsilon / \widetilde{\omega}=\omega) \int_{\Sigma}^{\varepsilon_{\max }} u^{\prime}(\pi) d \Psi_{\omega}(\varepsilon / \widetilde{\omega}=\omega)}{\Sigma}+\frac{\varepsilon_{\min }}{\Sigma}
$$

with

$\Sigma \equiv-\int_{\varepsilon_{\min }}^{\varepsilon_{\max }} u^{\prime}(\pi) d \Psi(\varepsilon / \widetilde{\omega}=\omega)+\frac{c^{\prime \prime}}{1+c^{\prime}} \int_{\varepsilon_{\min }}^{\varepsilon_{\operatorname{mix}}} u^{\prime}(\pi) d \Psi(\varepsilon / \widetilde{\omega}=\omega)+\left(1+c^{\prime}\right) A(\omega) \int_{\varepsilon_{\min }}^{\varepsilon_{\max }} u^{\prime}(\pi) d \Psi(\varepsilon / \widetilde{\omega}=\omega)>0$ where $\pi=\pi_{0}^{\prime}+g(x) \omega+k(x) \varepsilon+h(x)+I(\omega)-P, \quad w=w_{0}+P-I(\omega)-c(I(\omega)), \quad c^{\prime} \quad$ and $c^{\prime \prime}$ are evaluated at $I^{*}(\omega)$, and $A_{v} \equiv-v^{\prime \prime} / v^{\prime}$ is the insurer's index of absolute risk aversion. 
The proof of this proposition is shown in the Appendix. When the insurable climatic risk and the uninsurable aggregate production risk are independent, the design of an optimal insurance contract against a climatic experience contains a trigger level such that indemnity payments are made if the realized weather index falls below this trigger level. The numerator of the second right-hand side (RHS) ratio in equation (10) thus equals zero and therefore the slope of the optimal indemnity function is proportional to the marginal productivity of the weather index. When both sources of risk are correlated, the indemnity schedule can take basically any form without restrictions on the stochastic dependence and on the producer's behavior. If a decrease in $\omega$ induces a riskier conditional distribution of $\tilde{\varepsilon}$ in the sense of FSD, then the risk-averse producer's optimal insurance design contains a trigger level under which indemnity payments are made. It should be noted that if $\widetilde{\varepsilon}$ is a positive linear function of $\tilde{\omega}$ :

$$
\widetilde{\varepsilon}=\alpha+\beta \widetilde{\omega}+\tilde{e} \text { with } \beta>0
$$

where $\tilde{e}$ and $\widetilde{\omega}$ are stochastically independent and $E \tilde{e}=0$, then the cumulative distribution of $\tilde{\varepsilon}$ conditional on $\tilde{\omega}=\omega, \Psi(. / \widetilde{\omega}=\omega)$, increases as $\omega$ decreases. Hence, this positive linear relationship between an insurable risk and an uninsurable background risk, which has been recently analyzed by Mahul in the context of the area yield insurance program, is a particular case of an increase in risk in the sense of FSD.

Risk-aversion is not sufficient to characterize the optimal indemnity schedule if the cumulative distribution of $\widetilde{\varepsilon}$ conditional on $\widetilde{\omega}=\omega$ becomes riskier in the sense of SSD as $\omega$ decreases. The producer must also exhibit a convex marginal utility function, $u^{\prime \prime \prime}>0$, which is a well-known condition introduced by Leland. Kimball defines the term "prudent" to characterize agents who behave in this way and he offers the following economic interpretation: "prudence is meant to suggest the propensity to prepare and forearm oneself in the face of uncertainty, in contrast to risk-aversion which is how much one dislikes uncertainty and would turn away from uncertainty if one could." Hence, in the intertemporal model of saving under uncertainty, prudence represents the intensity of the precautionary saving motive. 
It is also a necessary condition for decreasing absolute risk aversion. The concept of prudence has been recently stressed by Gollier in order to examine the problem of the optimal form of the insurance contract when the indemnity can be contingent only upon an imperfect signal of the final wealth of the policyholder. Let us assume that the conditional expectation of the aggregate production level is inversely proportional to the realized weather index:

$$
\tilde{\varepsilon}=\frac{\tilde{e}}{\tilde{\omega}}
$$

where $\tilde{e}$ and $\tilde{\omega}$ are stochastically independent and $E \tilde{e}=0$, it is straightforward to show that $\Psi(. / \widetilde{\omega}=\omega)$ decreases with $\varepsilon \leq 0$ and increases otherwise. Since we have $E[\tilde{\varepsilon} / \widetilde{\omega}=\omega]=E \tilde{e}=0$, this stochastic relationship is thus a particular case of an increase in risk according to (3).

The following proposition, for which the proof is given in the Appendix, defines the effect of transaction costs on the trigger weather index selected by the producer.

\section{PROPOSITTON 2.}

Under the same assumptions as in Proposition 1, the optimal contract provides full insurance against the weather event, i.e. $\hat{\omega}=\omega_{\max }$, if insurance is costless, i.e. $c^{\prime}(I)=0$ for all $I$, and it provides partial insurance, i.e. $\hat{\omega}<\omega_{\max }$, if insurance is costly, i.e. $c^{\prime}(I)>0$ for all $I$.

\section{Named Peril Crop Insurance Reconsidered}

Propositions 1 and 2 characterize the optimal insurance contract design against a specific weather event. Nevertheless, this first-best solution cannot be easily implemented in reality. Consequently, we consider the insurance policy $\left[I^{c}(),. P^{c}\right]$ where:

$$
I^{c}(\omega)=\phi \max [\hat{\omega}-\omega, 0]
$$


The producer selects a trigger weather index $\hat{\omega}$ such that indemnity payments are made if the realized weather index falls below it, and a coverage level $\phi \geq 0$. The insurance payoff thus depends only on the realized weather index and the producer is not required to demonstrate any loss. Consequently, moral hazard and adverse selection are essentially eliminated and administration costs are substantially reduced. Such an insurance contract belongs to the alternative insurance programs where the indemnity schedule is not based on producer's individual yield but rather on an index which is not affected by individual decisions, like area yield crop insurance.

The private insurance industry provides hail insurance or Named Peril Crop Insurance (NPCI) such as rain on tomatoes or on raisins, or citrus freeze. These named peril policies allow the producer to hedge against losses caused by a specific climatic event on individual yields. Indemnity payments of these insurance policies are based on individual yields and consequently this design basically differs from the insurance scheme $\left[I^{c}(),. P^{c}\right]$. It should also be noted that current named peril insurance policies allow the insurers to eliminate ex ante moral hazard because the frequency of a climatic experience is not affected by the farmer's actions. Nevertheless, they may generate ex post moral hazard, i.e. fraud, because a time-lag may exist between the occurrence of the natural disaster and the observation of its consequences on the individual yields, being likely to induce the producer to become careless about his insured crops. The insurance policy suggested in equation (13) prevents him from behaving fraudulently.

The optimal coverage level selected by the insured producer is derived from the first-best insurance design. It is worth noticing that the NPCI insurance market is incomplete not only because the aggregate production risk is not insurable, but also because the form of the insurance contract is restricted to be piecewise linear with the insurable weather index.

Throughout this section, we assume that the insurer in the competitive insurance market is risk-neutral and his administrative cost function is linear. The insurance premium is thus proportional to the expected indemnity. Therefore, 
under this common assumption of proportional loading, the optimal marginal indemnity function expressed in equation (10) becomes:

$$
I^{*}(\omega)=-g(x)+\frac{\int_{\min }^{\varepsilon_{\min }} u^{\prime}(\pi) d \Psi_{\omega}(\varepsilon / \tilde{\omega}=\omega)}{-\int_{\varepsilon_{\min }}^{\varepsilon_{\min }} u^{\prime \prime}(\pi) d \Psi(\varepsilon / \tilde{\omega}=\omega)}
$$

for all $\omega<\hat{\omega}$. The absolute value of the slope of the insurance policy is thus equal to the marginal productivity of the insurable weather index plus a ratio which depends on the stochastic relationship between both sources of uncertainty and on the producer's preferences. If the insured weather index and the uninsurable aggregate production risk are independent then this ratio equals zero. The following corollary is thus deduced.

\section{COROLlary 1.}

Under the assumption of proportional loading and if the uninsurable aggregate production risk is independent of the insurable climatic risk, then the optimal coverage level of the reconsidered NPCI contract is equal to the marginal productivity of the insurable weather index, $\phi^{*}=g(x)$.

Integrating the numerator of the RHS ratio in equation (14) by parts once and twice yields for all $\omega<\hat{\omega}$, respectively:

$$
I^{*}(\omega)=-g(x)+k(x) \frac{\int_{\varepsilon_{\min }}^{\varepsilon_{\operatorname{mix}}} u^{\prime \prime}(\pi) \Psi_{\omega}(\varepsilon / \widetilde{\omega}=\omega) d \varepsilon}{\int_{\varepsilon_{\min }}^{\varepsilon_{\operatorname{mix}}} u^{\prime \prime}(\pi) d \Psi(\varepsilon / \widetilde{\omega}=\omega)}
$$

and 


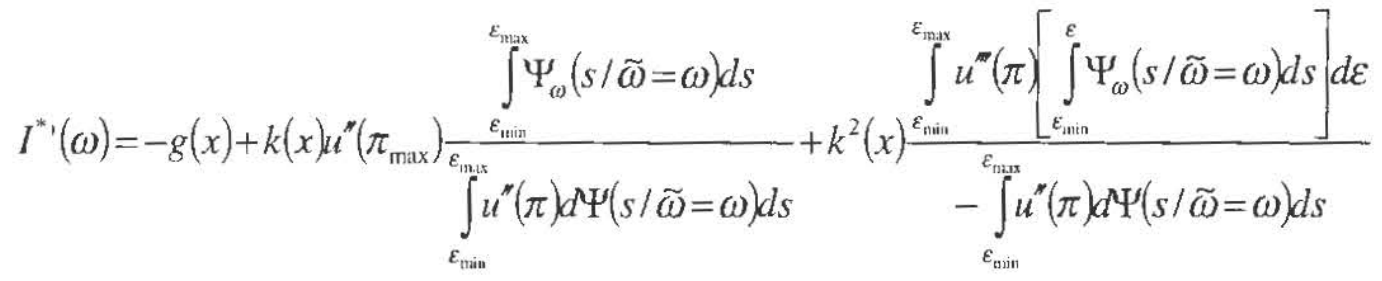

where $\pi_{\max }=\pi_{0}^{\prime}+g(x) \omega+k(x) \varepsilon_{\max }+h(x)+I^{*}(\omega)-P$. Consequently, the ratio in equation (15a) is negative if the producer is risk-averse and if a decrease in $\omega$ induces a riskier conditional distribution of $\widetilde{\varepsilon}$ in the sense of FSD. Both ratios in equation (15b) are also negative if the risk-averse producer is prudent and if a decrease in $\omega$ induces a riskier conditional distribution of $\tilde{\varepsilon}$ in the sense of SSD. We thus deduce the following corollary.

\section{Corollary 2.}

Suppose the insurance premium is proportional to the expected indemnity and one of both following assumptions is satisfied:

(i) the producer is risk-averse and a decrease in the insurable weather index makes the uninsurable aggregate production variable riskier according to (2);

(ii) the risk-averse producer is prudent and a decrease in the insurable weather index makes the uninsurable aggregate production variable riskier according to (3);

then the optimal coverage level of the reconsidered named peril crop insurance contract is higher than the marginal productivity of the insurable weather variable, $\phi^{*}>g(x)$.

When both sources of uncertainty are correlated, the risk-averse and prudent producer tries to hedge against the uninsurable aggregate production risk by selecting a coverage level higher than the marginal productivity of the weather index. It is of interest to notice that if $\widetilde{\varepsilon}$ depends on $\widetilde{\omega}$ according to the positive linear relationship (11), then one can easily show that the coverage level selected 
by the risk-averse producer is $\phi^{*}=g(x)+\beta k(x)$, with $\beta \geq 0$. It is thus equal to the sum of the marginal productivity of both risks weighted by the regression coefficient $\beta$.

Until now, we have assumed that the aggregate production variable $\tilde{\varepsilon}$ became riskier as the realized weather variable $\omega$ decreased, according to conditions (2) or (3). Nevertheless, it could be also realistic to assume that $\widetilde{\varepsilon}$ becomes riskier as $\omega$ increases. For example, an increase in the cumulative rainfall level could be in favor of the development of disease and insect infestation. Formally, we define the following increases in risk according to the first- and second-order stochastic dominance:

$$
\begin{aligned}
& \Psi_{\omega}(\varepsilon / \widetilde{\omega}=\omega) \geq 0 \text { for all } \varepsilon \text { and } \omega \\
& \int_{\varepsilon_{\mathrm{mun}}}^{\varepsilon} \Psi_{\omega}(s / \widetilde{\omega}=\omega) d s \geq 0 \text { for all } \varepsilon \text { and } \omega
\end{aligned}
$$

Without additional restrictions to these increases in risk, the indemnity function can basically take any form. ${ }^{1}$ Hence, we examine specific increases in risk according to (16) and (17). First, if $\widetilde{\varepsilon}$ is a negative linear function of $\widetilde{\omega}$ :

$$
\widetilde{\varepsilon}=\alpha+\beta \widetilde{\omega}+\widetilde{e} \text { with } \beta<0
$$

where $\widetilde{e}$ and $\widetilde{\omega}$ are stochastically independent and $E \widetilde{e}=0$, then this increase in risk satisfies (16). It is straightforward to show that $\phi^{*}=g(x)+\beta k(x)<g(x)$ if $0>\beta>-k(x) / g(x)$. If $\beta \leq-k(x) / g(x)$, the producer does not purchase the reconsidered NPCI policy, i.e. $\phi^{*}=0$. Second, assume that the conditional expectation of $\widetilde{\varepsilon}$ is proportional to the realized weather index $\omega$ :

$$
\widetilde{\varepsilon}=\tilde{\omega} \tilde{e}
$$

where $\tilde{e}$ and $\widetilde{\omega}$ are stochastically independent and $E \tilde{e}=0$. One easily shows that this increase in risk satisfies (17). The stochastic production function becomes

$$
\tilde{y}=[g(x)+k(x) \tilde{e}] \tilde{\omega}+h(x)
$$

Using the same arguments as those developed in the proof of Proposition 1, one can show that $\phi^{*}<g(x)$ if the following condition is also satisfied: 
(20b)

$$
g(x)+k(x) e \geq 0 \text { for all } e .
$$

This means that yield always increases with the insurable weather index whatever the realization of the aggregate production variable. ${ }^{2}$ This discussion on the effect of an alternative stochastic dependence on the optimal coverage level is summarized in the following corollary.

\section{Corollary 3.}

Suppose the insurance premium is proportional to the expected indemnity and one of both following assumptions is satisfied:

(i) the producer is risk-averse and an increase in the insurable weather index makes the uninsurable aggregate production variable riskier according to (18);

(ii) the risk-averse producer is prudent and an increase in the insurable weather index makes the uninsurable aggregate production variable riskier according to (20);

then the optimal coverage level of the reconsidered NPCI contract is lower than the marginal productivity of the insurable weather index, $0 \leq \phi^{*}<g(x)$.

\section{Input Response to Reconsidered NPCI Contract}

Until now, the design of an optimal insurance contract against a specific weather event and the producer's reconsidered NPCI purchasing decision have been analyzed under a fixed level of input use. In this section, we examine how buying this alternative insurance program alters the input level. We focus on the simplest case where the input use affects the output level only through the insurable weather index. The stochastic production function is thus assumed to be:

$$
\tilde{y}=g(x) \tilde{\omega}+h(x)+\tilde{\varepsilon}
$$

where $\widetilde{\omega}$ and $\widetilde{\varepsilon}$ are independent. ${ }^{3}$ The input is either risk-decreasing like pesticides, or risk-increasing like fertilizers, depending on whether the productivity is higher or lower in more adverse states of nature. This implies that the marginal productivity of the input $g^{\prime}($.) is negative or positive respectively. 
From Corollary 1, the indemnity function of the reconsidered NPCI contract is rewritten:

$$
I^{c}(\omega)=g(x) J(\omega) \text { with } J(\omega)=\max (\hat{\omega}-\omega, 0)
$$

where the trigger weather index $\hat{\omega}$ is fixed ${ }^{4}$, for example at its historic average. In addition, the insurance contract is assumed actuarially fair, i.e. $P^{c}=E I^{c}(\tilde{\omega})=g(x) Q$ with $Q=E J(\tilde{\omega})$. It should be pointed out that the insurance premium $P^{c}$ depends on the level of input use selected by the producer, contrary to the premium associated with the standard insurance contract based on individual yield (Ramaswami).

If the reconsidered NPCI policy is not available, the optimal choice of $x$ is dictated by:

$$
\max _{x} U(x, 0,0)=E \hat{u}\left(\tilde{\pi}_{n i}(x)\right)
$$

where $\pi_{n i}(x)=\pi_{0}+g(x) \omega+h(x)-p x$ and the indirect utility function is defined as

$$
\hat{u}(\pi)=E u(\pi+\widetilde{\varepsilon}) \text { for all } \pi \text {. }
$$

The optimal level of input use $x^{n i}$ satisfies the first-order necessary condition

$$
U_{x}\left(x^{n i}, 0,0\right)=g^{\prime}\left(x^{n i}\right) \mu+h^{\prime}\left(x^{n i}\right)-p-\left\{-g^{\prime}\left(x^{n i}\right) \frac{\operatorname{cov}\left[\widetilde{\omega}, \hat{u}^{\prime}\left(\tilde{\pi}_{n i}\left(x^{n i}\right)\right)\right]}{E \hat{u}^{\prime}\left(\tilde{\pi}_{n i}\left(x^{n i}\right)\right)}\right\}=0
$$

and the second-order condition is satisfied if $g($.$) and h($.$) are concave in x$ and the producer is risk-averse. The term in brackets in the above equation is the marginal risk premium of the input when there is no insurance contract. It is null if the producer is risk-neutral. Under risk-aversion it is positive (resp. negative) if the input is risk-increasing (resp. risk-decreasing).

When the reconsidered NPCI policy $\left\langle I^{c}, P^{c}\right\rfloor$ is available the producer maximizes the following objective function:

$$
U\left(x, I^{c}, P^{c}\right)=E \hat{u}\left(\tilde{\pi}_{i}(x)\right)
$$

where $\pi_{i}(x)=\pi_{n i}(x)+I^{c}(\omega)-P^{c}=\pi_{n i}(x)+g(x)[J(\omega)-Q]$

The optimal level of input use $x^{i}$ satisfies: 


$$
U_{x}\left(x^{i}, I, P\right)=g^{\prime}\left(x^{i}\right) \mu+h^{\prime}\left(x^{i}\right)-p+g^{\prime}\left(x^{i}\right) \frac{\operatorname{cov}\left[\tilde{\omega}, \hat{u}^{\prime}\left(\tilde{\pi}_{i}\left(x^{i}\right)\right)\right]}{E \hat{u}^{\prime}\left(\tilde{\pi}_{i}\left(x^{i}\right)\right)}-g^{\prime}\left(x^{i}\right) \frac{\operatorname{cov}\left[J(\tilde{\omega}), \hat{u}^{\prime}\left(\tilde{\pi}_{i}\left(x^{i}\right)\right)\right]}{E \hat{u}^{\prime}\left(\tilde{\pi}_{i}\left(x^{i}\right)\right)}=0
$$

where $E\left[(J(\tilde{\omega})-Q) \hat{u}^{\prime}\left(\tilde{\pi}_{i}\left(x^{i}\right)\right)\right]=\operatorname{cov}\left[J(\tilde{\omega}), \hat{u}^{\prime}\left(\tilde{\pi}_{i}\left(x^{i}\right)\right)\right]$ under actuarially fair insurance. Compared with equation (25), there is an additional term represented by the last RHS term in equation (27). It characterizes the impact of the actuarially fair reconsidered NPCI policy on the producer's input decision. Since the objective function $U(x, 0,0)$ is concave in $x$, we deduce that $x^{i} \leq(\geq) x^{n i}$ as $U_{x}\left(x^{i}, 0,0\right) \geq(\leq) 0$. From equations $(25)$ and $(27)$, this inequality is rewritten:

$$
g^{\prime}\left(x^{i}\right) \operatorname{cov}\left[\widetilde{\omega}, T\left(x^{i}, \widetilde{\omega}\right)\right]+g^{\prime}\left(x^{i}\right) \frac{\operatorname{cov}\left[J(\tilde{\omega}), \hat{u}^{\prime}\left(\tilde{\pi}_{i}\left(x^{i}\right)\right)\right]}{-E \hat{u}^{\prime}\left(\tilde{\pi}_{i}\left(x^{i}\right)\right)} \geq(\leq) 0
$$

where

$$
T(x, \omega)=\frac{\hat{u}^{\prime}\left(\tilde{\pi}_{n i}(x)\right)}{E \hat{u}^{\prime}\left(\tilde{\pi}_{n i}(x)\right)}-\frac{\hat{u}^{\prime}\left(\tilde{\pi}_{i}(x)\right)}{E \hat{u}^{\prime}\left(\tilde{\pi}_{i}(x)\right)}
$$

The first term in the above inequality represents the difference between the marginal risk premiums of the input with and without the reconsidered NPCI contract. It can be shown (see the Appendix) that if the insurance premium is actuarially fair and the risk-averse producer exhibits prudence, then $\operatorname{cov}[\widetilde{\omega}, T(x, \widetilde{\omega})] \leq 0$ for all $x$. This first term is thus positive or negative depending on whether the input is risk-decreasing or risk-increasing.

The second covariance term in equation (28a) depends on the shape of $J$ and $\hat{u}^{\prime}\left(\tilde{\pi}_{i}\right)$ with respect to $\omega$. The indemnity function $J$ is nonincreasing with $\omega$ and the profit function $\pi_{i}$ is nondecreasing with $\omega$. Since the producer's risk-aversion implies that the indirect utility function $\hat{u}$ is concave (Kihlstrom, Romer and Williams), we deduce that $\operatorname{cov}\left[J(\tilde{\omega}), \hat{u}^{\prime}\left(\tilde{\pi}_{i}(x)\right)\right]$ is positive. The second term in equation (28a) is thus positive (resp. negative) if the input is risk-decreasing (resp. risk-increasing). This discussion is summarized in the following proposition. 


\section{PROPOSITION 3.}

The purchase of an actuarially fair NPCI contract induces the risk-averse and prudent producer to (i) increase his level of risk-increasing input use and (ii) decrease his level of risk-decreasing input use

Ramaswami examines how the purchase of a multiple peril crop insurance contract in which indemnity payments are based on the producer's individual yield alters his input decision. He shows that under constant or decreasing absolute riskaversion, the impact of an actuarially fair crop insurance on input use is to reduce it if the input is risk-decreasing and it is indeterminate if the input is riskincreasing. This result stems from the comparison of two effects. The riskreduction effect induces the producer to increase his exposure towards risk by reducing (resp. increasing) his level of risk-decreasing (resp. risk-increasing) input use. The second effect is due to ex ante moral hazard: the purchase of insurance leads the producer to alter his input decisions and thus the distribution of the individual yields. These changes cannot be observed by insurers and, consequently, they cannot be taken into account in the calculation of the insurance premium. This moral hazard effect thus leads the producer to reduce his consumption of either risk-increasing or risk-decreasing input. Under the reconsidered NPCI policy and more generally when the indemnity function is based on exogenous variable beyond the producer's decisions, changes in input use affect the insurance premium and therefore ex ante moral hazard does not exist. The impact of insurance purchase on the level of input use is thus unambiguous, even if the input is risk-increasing.

It is of interest to notice that if the actuarially fair NPCI contract provides a complete coverage against the climatic risk, i.e. the trigger weather variable $\hat{\omega}$ is equal to $\omega_{\max }$ which implies that $J(\omega)-Q=\mu-\omega$, then both ratios in equation (27) equal zero and, therefore, the producer adopts a risk neutral attitude towards the climatic risk by selecting a level of input use so that the expected marginal productivity equals the marginal cost. The insured risk-averse producer thus 
responds to the introduction of this insurance policy by increasing or decreasing his level of input use depending on whether it is risk-increasing or risk-decreasing. The assumption of prudence is not necessary in this specific case of global risk reduction. This result differs from the impact of a complete coverage offered by the multiple peril crop insurance contract where moral hazard effect does not provide any incentive for positive level of input use (Ramaswami).

\section{Optimal Hedging Decisions with Weather Derivatives}

Unfavorable weather events such as droughts or extreme temperatures simultaneously affect a large number of producers. Insurance contract against a weather event thus allows producers to hedge against this systemic component of crop risk. Nevertheless, systemic risk may pose the most serious obstacle to the emergence of an independent private crop insurance market because insurers are not able to pool this risk (Miranda and Glauber). Since the reinsurance industry is unwilling or unable to offer affordable reinsurance for such a risk, governments usually address this problem by instituting a public reinsurance program, like in the U.S. or in France. Financial markets have recently provided an alternative to these reinsurance programs by offering a range of products known as weather derivatives. They were initially conducted in the energy market but they could be easily adapted to cover weather risk in agricultural markets. A first attempt was made by Turvey in this agricultural context who introduced different weather derivatives and computes their premiums.

Thanks to the similarity between hedging instruments and insurance contracts, the reconsidered NPCI purchasing decision can be used to investigate the optimal hedging strategy on financial markets. It should be noticed that the indemnity function of the NPCI contract expressed in equation (13) can be reinterpreted as a put option where $\hat{\omega}$ is a strike weather index and $\phi$ is the amount of contracts purchased by the producer.

We first assume that the producer perceives hedging instruments to be fairly priced, i.e. financial markets are unbiased. From Propositions 1 and 2, the risk- 
averse producer's optimal hedge thus requires a futures position since the firstbest hedging strategy displays an indemnity function which is always positive. From Corollary 1, this is a short futures position equal to the marginal productivity of the weather index if the unhedgeable aggregate production risk is independent of the hedgeable climatic risk. From Corollaries 2 and 3, the short futures position is higher (resp. lower) than this marginal productivity if a decrease (resp. increase) in the hedgeable weather index makes the unhedgeable aggregate production variable riskier according to equation (2) (resp. equations (20)). Under a linear relationship between both risks, as expressed in equations (11) or (18), the optimal hedging position is to sell or purchase $|g(x)+\beta k(x)|$ futures contracts depending on whether the regression coefficient $\beta$ is higher or lower than $-k(x) / g(x)$. In this particular case, the first-best hedging instrument is linear with the weather index and therefore options are redundant.

When financial markets are upward biased, i.e. the price of hedging instruments is higher than the expected payoffs, payments associated with the first-best indemnity function are made only when the realized weather index is lower than a trigger level. This entails that the optimal hedging strategy displays only options. Among other things, the optimal hedge requires put options with a strike weather variable equal to the optimal trigger level. Its optimal amount is equal to the amount of futures under unbiased markets with respect to the stochastic relationship between both sources of risk.

\section{Conclusion}

Recent developments in the theory of insurance under incomplete markets have been used to design an optimal insurance contract against a specific weather event like droughts or extreme temperatures. The optimal form of this insurance policy has been shown to depend on the stochastic relationship between the insurable climatic risk and the uninsurable aggregate production risk and on individual behavior towards risk. It contains a trigger weather index under which indemnity payments are made (i) if the producer is risk-averse and if the aggregate 
production variable becomes riskier according to the first-order stochastic dominance as the weather index decreases, or (ii) if the risk-averse producer exhibits prudence and if the aggregate production variable becomes riskier according to the second-order stochastic dominance as the weather index decreases. Under the reconsidered named peril crop insurance program where indemnity payments are contingent on the intensity of the weather index rather than on its consequence on yield, the optimal coverage level has been shown to equal the marginal productivity of the weather index if both sources of production uncertainty are independent. It is higher than this marginal productivity if the aggregate production variable becomes riskier according to the second-order stochastic dominance as the weather index decreases and if the producer is prudent. Under a specific production function where both risks interact in a multiplicative manner the optimal coverage level of the prudent producer is lower than the marginal productivity. The level of input use is altered by the presence of such an insurance policy. When the input decision affects only the marginal productivity of the insurable climatic risk, the risk-averse and prudent producer responds to the introduction of such an actuarially fair insurance contract by increasing his exposure towards risk, i.e. by reducing his level of risk-decreasing input and by increasing his level of risk-increasing input.

The reconsidered named peril crop insurance contract can be viewed as a weather derivative. Therefore, these results are useful to derive the optimal futures hedge under unbiased financial markets and the optimal options hedge under upward biased financial markets. Since the first-best hedging strategy is not linear in the weather variable, except if a linear relationship exists between both sources of risk, a scope for options in addition to futures when financial markets are unbiased is introduced (Moschini and Lapan). Further research should thus analyze the curvature of the optimal indemnity function in order to investigate the optimal options hedge. 


\section{References}

Bardsley, P., A. Abey and A. Davenport. "The Economics of Insuring Crops Against Drought." Australian Journal of Agricultural Economics 28(ApriI 1984): 1-14.

Doherty, N. and G. Dionne. "Insurance with Undiversifiable Risk: Contract Structure and Organizational Form of Insurance Firms." Journal of Risk and Uncertainty 6(1993): 187-203.

Gollier, C. "Optimum Insurance of Approximate Losses," Journal of Risk and Insurance 63(September 1996): 369-380.

Just, R.E. and R.D. Pope. "Production Function Estimation and Related Risk Considerations." American Journal of Agricultural Economics 61(May 1979): $277-284$.

Kaufmann, R. and S. Snell. "A Biological Model of Corn Yield: Integrating Climatic and Social Determinants." American Journal of Agricultural Economics 79(February 1997), 178-190.

Kihlstrom, R., Romer, D. and Williams, S. "Risk Aversion with Random Initial Wealth." Econometrica 49(July 1981): 911-920.

Kimball, M.S. "Precautionary Saving in the Small and in the Large." Econometrica 58( January 1990): 53-73.

Leland, H. E. "Saving and Uncertainty: the Precautionary Demand for Saving." Quarterly Journal of Economics 82(1968): 465-473.

Mahul, O. "Optimum Area Yield Crop Insurance." American Journal of Agricultural Economics 81(February 1999): 75-82.

Miranda, M.J. and J.W. Glauber. "Systemic Risk, Reinsurance, and the Failure of Crop Insurance Markets." American Journal of Agricultural Economics 79(February 1997): 206-215.

Moschini, G. and H. Lapan. "Hedging Price Risk with Options and Futures for the Competitive Firm with Production Flexibility." International Economic Review 33(August 1992): 607-618. 
Patrick, G.F. "Mallee Wheat Farmers' Demand for Crop and rainfall Insurance." Australian Journal of Agricultural Economics 32(April 1988): 37-49.

Quiggin, J. "A Note on the Viability of Rainfall Insurance." Australian Journal of Agricultural Economics 30(April 1986): 63-69.

Quiggin, J. "The Optimal Design of Crop Insurance," Economics of Agricultural Crop Insurance: Theory and Evidence. D.L. Hueth and W.H. Furtan, eds., Norrwell MA: Kluwer Academic Publishers, pp. 115-134, 1994.

Ramaswami, B. "Supply Response to Agricultural Insurance: Risk Reduction and Moral Hazard Effects." American Journal of Agricultural Economics 75(November 1993): 914-925.

Raviv, A. "The Design of an Optimal Insurance Policy." American Economic Review 69(March 1979): 84-96.

Sanderson, F. "A Specific-Risk Scheme for Wheat Crop Insurance." Journal of Farm Economics 25(1943): 459-776.

Skees, J., J.R. Black, and B.J. Barnett. "Designing and Rating an Area Yield Crop Insurance Contract." American Journal of Agricultural Economics 79(May 1997): 233-42.

Turvey, C. "Weather Derivatives and Specific Event Risk." Paper presented at the Annual Meeting of the AAEA, Nashville TN, August 8-11 1999. 


\section{Appendix}

\section{Proof of Proposition I}

The objective function of problem (8) can be rewritten

$$
\int_{\omega_{\min }}^{\omega_{\max }} \int_{\varepsilon_{\min }}^{\varepsilon_{\max }} u\left(\pi_{0}^{\prime}+g(x) \omega+k(x) \varepsilon+h(x)+I(\omega)-P\right) d T(\omega, \varepsilon)
$$

where $d T(\omega, \varepsilon)=d \Psi(\varepsilon / \widetilde{\omega}=\omega) d \Phi(\omega)$. The Hamiltonian of the maximization problem is thus

$$
H=\left\{\int_{\varepsilon_{\min }}^{\varepsilon_{\min }} u(\pi) d \Psi(\varepsilon / \tilde{\omega}=\omega)+\zeta v(w)\right\} d \Phi(\omega)
$$

where $\pi=\pi_{0}^{\prime}+g(x) \omega+k(x) \varepsilon+h(x)+I(\omega)-P$ and $w=w_{0}+P-I(\omega)-c(I(\omega))$. As already shown by Raviv (1979), the multiplier function $\zeta$ is constant with respect to $\omega$. The first-order necessary conditions are:

$$
I^{*}(\omega)=0 \text { if } K(\omega)=\int_{\varepsilon_{\min }}^{\varepsilon_{\max }} u^{\prime}\left(\pi_{1}\right) d \Psi(\varepsilon / \widetilde{\omega}=\omega)-\zeta\left[1+c^{\prime}(0)\right] v^{\prime}\left(w_{0}+P\right) \leq 0
$$

where $\pi_{1}=\pi_{0}^{\prime}+g(x) \omega+h(x)-P+k(x) \varepsilon$ and

$$
I^{*}(\omega)>0 \text { if } \int_{\varepsilon_{\min }}^{\varepsilon_{\operatorname{mix}}} u^{\prime}(\pi) d \Psi(\varepsilon / \tilde{\omega}=\omega)-\zeta\left[1+c^{\prime}\left(I^{*}(\omega)\right)\right] v^{\prime}(w)=0
$$

The first derivative of $K$ with respect to $\omega$ is:

$$
K^{\prime}(\omega)=g(x) \int_{\varepsilon_{\min }}^{\varepsilon_{\max }} u^{\prime \prime}\left(\pi_{1}\right) d \Psi(\varepsilon / \widetilde{\omega}=\omega)+\int_{\varepsilon_{\min }}^{\varepsilon_{\max }} u^{\prime}\left(\pi_{1}\right) d \Psi_{\omega}(\varepsilon / \widetilde{\omega}=\omega)
$$

First, notice that the first RHS term in (A5) is negative because the producer is risk-averse and $g($ ) is a positive function. Second, integrating the second RHS term in (A5) yields:

$$
\int_{\varepsilon_{\min }}^{\varepsilon_{\max }} u^{\prime}\left(\pi_{1}\right) d \Psi_{\omega}(\varepsilon / \widetilde{\omega}=\omega)=-k(x) \int_{\varepsilon_{\min }}^{\varepsilon_{\max }} u^{\prime \prime}\left(\pi_{1}\right) \Psi_{\omega}(\varepsilon / \widetilde{\omega}=\omega) d \varepsilon
$$

with $\Psi_{\omega}\left(\varepsilon_{\min } / \tilde{\omega}=\omega\right)=\Psi\left(\varepsilon_{\max } / \tilde{\omega}=\omega\right)=0$. Since we have $k()>$.0 , the above expression is negative if the producer is risk-averse and if assumption (2) is satisfied. Third, integrating again the RHS term of equation (A6) yields: 
(A7)

$$
\begin{aligned}
& \int_{\varepsilon_{\text {mix }}}^{\varepsilon_{\operatorname{mix}}} u^{\prime}\left(\pi_{1}\right) d \Psi_{\omega}(\varepsilon / \widetilde{\omega}=\omega)= \\
& -k(x) u^{\prime \prime}\left(\pi_{1 \operatorname{mix}}\right) \int_{\varepsilon_{\min }}^{\varepsilon_{\max }} \Psi_{\omega}(s / \widetilde{\omega}=\omega) d s+k^{2}(x) \int_{\varepsilon_{\min }}^{\varepsilon_{\max }} u^{\prime \prime \prime}\left(\pi_{1}\right)\left[\int_{\varepsilon_{\operatorname{mux}}}^{\varepsilon} \Psi_{\omega}(s / \widetilde{\omega}=\omega) d s\right] d \varepsilon
\end{aligned}
$$

where $\pi_{1 \max }=\pi_{0}^{\prime}+g(x) \omega+h(x)-P+k(x) \varepsilon_{\max }$. The above expression is negative if $u^{\prime \prime}<0, u^{\prime \prime \prime}>0$ and assumption (3) is satisfied.

Consequently, $K$ decreases with $\omega$ if the producer is risk-averse, $u^{\prime \prime}<0$, and if a decrease in $\omega$ induces a riskier conditional distribution of $\widetilde{\varepsilon}$ in the sense of FSD. It also decreases if the risk-averse producer is prudent, $u^{\prime \prime \prime}>0$, and if a decrease in $\omega$ induces a riskier conditional distribution of $\widetilde{\varepsilon}$ in the sense of SSD. Finally, if the random variables are independently distributed, we have $\Psi_{\omega}(\varepsilon / \tilde{\omega}=\omega)=0$ for all $\varepsilon$ and $\omega$ and, therefore, $K$ decreases under riskaversion. In these three cases, a trigger level $\hat{\omega}$ exists such that $(\hat{\omega}-\omega) K(\omega) \geq 0$ for all $\omega$. Therefore, we deduce the optimal form of the insurance contract expressed in equation (9). Finally, differentiating equation (A4) with respect to $\omega: I^{*}(\omega)>0$ yields equation $(10)$.

\section{Proof of Proposition 2}

Let the function $\lambda(\omega)$ be such that:

$$
\int_{\varepsilon_{\operatorname{man}}}^{\varepsilon_{\max }} u^{\prime}(\pi) d \Psi(\varepsilon / \widetilde{\omega}=\omega)-\zeta\left[1+c^{\prime}\left(I^{*}(\omega)\right)\right] y^{\prime}(w)+\lambda(\omega)=0
$$

for all $\omega \in\left[\omega_{\min }, \omega_{\max }\right]$. From first-order necessary conditions (A3) and (A4), $\lambda(\omega)=0$ if $I^{*}(\omega)>0$ and $\lambda(\omega) \geq 0$ otherwise. The maximization of problem (8) with respect to the premium $P$ yields:

$$
\zeta=\frac{E\left\{E\left[u^{\prime}(\tilde{\pi}) / \tilde{\omega}=\omega\right]\right\}}{E v^{\prime}(\tilde{w})}
$$

Introducing (A9) in equation (A8) and taking the expectation with respect to $\widetilde{\omega}$ yield: 
(A10) $\quad E \lambda(\tilde{\omega})=\frac{E u^{\prime}(\tilde{\pi})}{E v^{\prime}(\tilde{w})} E\left[c^{\prime}\left(I^{*}(\tilde{\omega})\right) v^{\prime}(\tilde{\omega})\right]$

If $c^{\prime}(I)=0$ for all $I$, then $E \lambda(\widetilde{\omega})=0$. Since $\lambda($.$) is a nonnegative function, this$ entails that $\lambda(\omega)=0$ for all $\omega \in\left[\omega_{\min }, \omega_{\max }\right]$ and, consequently, $I^{*}(\omega)>0$ for all $\omega \in\left[\omega_{\min }, \omega_{\max }\right]$. This means that $\hat{\omega}=\omega_{\max }$. If $c^{\prime}(I)>0$ for some $I$, then we have $E \lambda(\widetilde{\omega})=0$. This implies that $I^{*}(\omega)=0$ for some $\omega$. Since $I^{*}($.$) is a decreasing$ function under risk-aversion and stochastic independence between both risks, or under risk-aversion and an FSD increase in risk, or under risk-aversion, prudence and an SSD increase in risk, the trigger weather index $\hat{\omega}$ is lower than $\omega_{\max }$.

Proof of the negativity of $\operatorname{cov}[\widetilde{\omega}, T(x, \widetilde{\omega})]$

Using the same arguments as those developed by Ramaswami (1993), we derive the following lemma.

LEMMA. If $Q=E J(\widetilde{\omega})$ and $u^{m} \geq 0$ then there exists $\omega^{*} \in\left[\omega_{\min }, \omega_{\max }\right]$ such that:

$$
T(x, \omega)\left(\omega^{*}-\omega\right) \geq 0 \text { for all } \omega \in\left[\omega_{\min }, \omega_{\max }\right]
$$

where

$T(x, \omega)=\frac{\hat{u}^{\prime}\left(\pi_{n i}(x)\right)}{E \hat{u}^{\prime}\left(\tilde{\pi}_{n i}(x)\right)}-\frac{\hat{u}^{\prime}\left(\pi_{i}(x)\right)}{E \hat{u}^{\prime}\left(\tilde{\pi}_{i}(x)\right)}, \pi_{n i}(x)=\pi_{0}+g(x) \omega+h(x)-p x$ and $\pi_{i}(x)=\pi_{n i}(x)+I^{c}(\omega)-P$.

It is worth noticing that Ramaswami derives this result under the assumption of nonincreasing absolute risk-aversion. The above lemma is thus less restrictive since the same result is obtained under prudence which is a necessary condition of nonincreasing absolute risk aversion. Therefore, we deduce from this lemma that:

$$
\int_{\omega_{\min }}^{\omega^{*}} \omega T(x, \omega) d \Phi(\omega) \leq \omega^{*} \int_{\omega_{\min }}^{\omega^{*}} T(x, \omega) d \Phi(\omega)
$$

and 
(A12) $\quad \int_{\omega^{*}}^{\omega_{\operatorname{mix}}} \omega T(x, \omega) d \Phi(\omega) \leq \omega^{*} \int_{\omega^{*}}^{\omega_{\max }} T(x, \omega) d \Phi(\omega)$

Consequently, we have

(A13) $\operatorname{cov}(\tilde{\omega}, T(x, \tilde{\omega}))=\int_{\omega_{\min }}^{\omega^{*}} \omega T(x, \omega) d \Phi(\omega)+\int_{\omega^{*}}^{\omega_{\max }} \omega T(x, \omega) d \Phi(\omega) \leq \omega^{*} E T(x, \tilde{\omega})=0$

This concludes the proof. 


\section{Notes}

1. Following the proof of Proposition 1, the first RHS term of $K^{\prime}$ expressed in equation (A5) is negative whereas its second RHS term is positive under the assumptions (16) or (17). The sign of $K^{\prime}$ is ambiguous and consequently the design of an optimal indemnity function is indeterminate.

2. Under assumption (20b), the function $K^{\prime}$ expressed in equation (A5) is negative for all $\omega$.

3. If $\widetilde{\omega}$ and $\widetilde{\varepsilon}$ are correlated, one can project orthogonally the aggregate production risk $\widetilde{\varepsilon}$ onto the random weather variable $\widetilde{\omega}$ :

$\tilde{\varepsilon}=\beta(\tilde{\omega}-\mu)+\tilde{e}$

where $\beta=\operatorname{cov}(\widetilde{\varepsilon}, \widetilde{\omega}) / \operatorname{var}(\widetilde{\omega}), E \tilde{e}=0, \tilde{\omega}$ and $\tilde{e}$ are independent. The stochastic production function can thus be rewritten:

$\tilde{y}=[g(x)+\beta] \tilde{\omega}+[h(x)-\beta \mu]+\tilde{e}$.

4. The trigger weather index $\hat{\omega}$ is assumed to be fixed at a sufficiently high value such that the optimal coverage level $\phi^{*}$ is equal to $g(x)$. This assumption on $\hat{\omega}$ is realistic because insurance policy does not generate moral hazard and therefore there is no reason to introduce a large deductible to encourage the producer to self-protect. If $\hat{\omega}$ was to low, the producer may be induced to choose a coverage level which could be different from $g(x)$. 